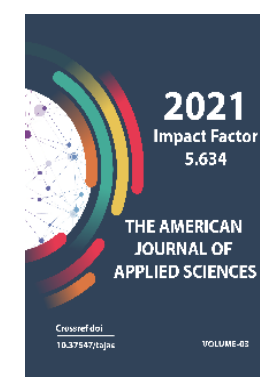

Journal Website:

http://theamericanjour nals.com/index.php/taj as

Copyright: Original content from this work may be used under the terms of the creative commons attributes 4.0 licence.

\title{
Electrochemical Reduction Of Macroiones As A Surface- Active Nanocoating And Nanocomposites
}

\author{
J.M. Khakkulov \\ National University Of Uzbekistan, University Str., 4, Tashkent, Uzbekistan \\ Z.Sh. Temirov \\ National University Of Uzbekistan, University Str., 4, Tashkent, Uzbekistan \\ Sh.E. Khalilov \\ National University Of Uzbekistan, University Str., 4, Tashkent, Uzbekistan
}

\section{ABSTRACT}

The possibilities of the application and efficiency of electric fields in the process of electrolysis of macroions from solutions were studied. The restoration of local natural and synthetic ionic polymers on a titanium implant in the form of surface-active nanocoatings and nanocomposites by electrolysis is shown. The structural characteristics of the obtained nanomaterials are studied.

\section{KEYWORDS}

Electrolysis, nanocoating, nanocomposites, surface activity, fibroin, chitosan, tribasic calcium phosphate.

\section{INTRODUCTION}

Obtaining polymeric nanostructured materials, in particular, nanocoatings with special functional properties, seems to be one of the promising scientific problems of modern nanomaterial science and nanotechnology [1-3]. Such nanocoatings can be formed by electrolysis, i.e. electrochemical reduction of ionic polymer macromolecules, i.e. macroions from solutions on the surface of electrodes of various shapes $[4,5]$. In the case of choosing medical implants as an electrode for macro ion reduction, it is very important to have the obtained nanocoatings with the property of biocompatibility, bioactivity, nontoxicity, etc. This was the subject of a number of targeted scientific studies and it was shown that it is possible in principle to use the electrolysis method to form a micro-sized coating on the surface of a titanium dental implant based on chitosan biopolymer having its own bioactivity due to the presence of an amine $\left(\mathrm{NH}_{2}+\right)$ group in the elementary units 
of its polysaccharide chain [6]. The widespread use of chitosan is to some extent difficult due to the production of this polysaccharide by using a high-tech method of deacetylation of a chitin biopolymer released from the protective coating of the external organs of various small living creatures, such as crabs, crayfish, fish, pupae, etc. [7-10].

In principle, chitosan can be replaced with other more accessible, less laborious to obtain biopolymers, in particular, natural proteins such as silk fibroin (FB), which do not require preliminary chemical modification for use in electrolysis [11]. In contrast to chitosan, in the elementary link of fibroin, along with the amine group, there is a functionally active carboxyl ( $\mathrm{COOH}-)$ group. In principle, such multivalent groups contribute to the selective interaction of proteins with various substances, especially ions and ionic compounds. It should be noted that the content in fibroin of relatively bulky amino acid residues such as aspartic and glutamic acids does not fully allow the formation of $a$ helices of the molecules of this protein in solution, as well as $\beta$-forms in the resulting material [12]. Such a structural feature of fibroin molecules can affect the obtaining of a uniform coating structure during electrolysis, i.e. all ionogenic groups of large amino acid residues cannot come close enough to the surface of the electrode for electrochemical reduction. In this case, there will be places not restored in the coating structure, i.e. residual ionogenic groups, which, in fact, contribute to an increase in the surface activity of the final material.

Unlike low-molecular-weight ions, the movement of macroions to the electrode and subsequent reduction realized under the influence of an electric field largely depends on the molecular mass and conformation of the ionic polymer, as well as the nature of its polyelectrolyte solution or mixture [13-15]. An important role in this is the preparation of the electrode with a certain surface relief. If we take into account that most biopolymers, including fibroin molecules, are characterized by a diameter of about $1 \mathrm{~nm}$ and a length of more than $500 \mathrm{~nm}$ [16], then the restoration of such ionogenic compounds will be accompanied by the formation of strong chemical bonds, when this process is carried out in micro-sized rough cavities, previously deposited on the surface of the electrode. In this, the formation of chemical bonds of macroions is possible, not only with the bottom, but also with the inner side walls of the recess. In this case, the point of chemical bonds of macroions with the electrode rises, which contributes to the strong fixing of the biopolymer on the surface.

It should be noted high mobility for the recovery of low molecular weight ions compared with macroions. In the case of the presence of multivalent ions in a biopolymer solution, the formation of a polymer-ion complex is inevitable. And when the supramolecular structure of the coating is formed, multivalent ions can play the role of a binding polymer to the surface, especially when the surface has recesses. Such low molecular weight compounds may be multivalent ions, for example, three calcium phosphate, which is biocompatible and is used to cover dentures [17-18]. Based on the dimensional parameters of ions and macroions, as well as their mobility in an electric field, it can be assumed that pentavalent phosphate ions are more efficiently restored in surface recesses of an 
electrode compared to macroions of a biopolymer. Therefore, the use of three calcium phosphate as a binder and filler in the reduction of fibroin macroions in the form of a coating matrix is of great interest. Of particular importance is the improvement of the electrolysis method using an oxidation electrode that does not create side compounds and impurities in the solution for the full implementation of the process of electrochemical reduction of biopolymer macroions in the presence of multivalent low molecular weight ions [19-20]. Such an electrode can be carbon, for example, graphite rods [21]. It is also important to select the optimal concentration, temperature and viscosity of the solution, direct current and voltage, since the movement of macroions during electrolysis depends on the influence of these factors. In this, the temperature can be controlled using a thermostatic solution tank.

In general, it seems that the electrolysis of the formation of nanocoatings of biopolymers from polyelectrolyte solutions is complex. It can be used to obtain fibroin-based nanocoatings from polyampholitic solutions by conducting in-depth exploratory studies to determine the optimal conditions for the movement and reduction of macroions of a given protein in the presence of three calcium phosphate ions on the surface, for example, of a titanium electrode of various shapes and topography. It should be noted that as the main object of study, the selected biopolymer fibroin is a fibrillar protein, the basis of fibers of natural silk. A fibroin fiber can be isolated from a silk cocoon by rinsing from natural ingredients such as bioclue sericin, grease wax and minerals. The elementary units of fibroin molecules differ in the content of amino acid residues, but have a common empirical structure of $\mathrm{C}_{13} \mathrm{H}_{23} \mathrm{~N}_{5} \mathrm{O} 6$ and are characterized by an average molecular weight of 345 [22]. The elementary unit includes carboxyl and amine groups, which, being very active, contribute to the formation of various molecular and supramolecular structures of the protein. Namely, as a result of the interaction of these groups, intramolecular $\alpha$-helices or intermolecular $\beta$-structures, gel structures, and fibroin crystals are formed. With this in mind, the present work was carried out in which studies were conducted in a specially assembled electrolysis unit for macroions of biopolymers.

\section{EXPERIMENTAL METHODS}

The initial object - fibroin fiber was isolated from the composition of the cocoon of natural silk by sequential washing of natural components: - sericin in a $5 \%$ aqueous solution of sodium bicarbonate $\left(\mathrm{NaHCO}_{3}\right)$ at $50^{\circ} \mathrm{C}$ for 1 hour; - fatty and minerals in acetone on the Soxhlet apparatus [18]; - the isolated fibroin fibers were dried under room condition. Fibroin fiber has a thickness of about $10 \mu \mathrm{m}$, is characterized by an amorphous-crystalline structure and exhibits pronounced optical anisotropy in the visible spectrum [19]. This structural feature of fibroin fibers made it possible to conduct polarization-microscopic control of the processes occurring during washing and to evaluate the degree of purification of the isolated fiber product. Thus, the obtained fibroin fibers accounted for $\approx 72 \%$ of the initial mass of silk cocoon, which is in good agreement with published data [20].

The average molecular weight $(M)$ of fibroin was determined by the method of Ubbelohde 
viscometer [21]. For this, a $1 \%$ solution of fibroin 2.5 M LiCl-DMF was prepared, the characteristic viscosity $[\eta]$ was measured and the molecular weight was calculated according to the Mark-Kun-Houwink equation: $M \approx\left([\eta] / 1,23^{*} 10^{-3}\right)^{1 / 0.91}$. The behavior of fibroin macroions during the flow of solutions was studied using a «Reotest-2» rheometer (Germany) [22]. The electrochemical reduction of fibroin macroions was carried out on a specially assembled electrolysis unit, schematically shown in Fig. 1. The installation consists of three main parts, namely, a glass cylindrical tank (R), electrical (E) and optical (O) system. The tank (volume $1 \mathrm{l}$ ) has a thermostatically controlled shirt (1) and an optical window $(2,2 *)$ mounted on an electric mixer (3). The solution contains a solution (4) in which the oxidation (5) and reduction (6) electrodes are lowered at the level of the optical window. The rotation of the magnet (7) by means of an electric mixer provides intensive movement of the solution. The temperature of the solution is maintained using a water thermostat connected to the tank through fittings $(8)$ and $(8 *)$. The temperature of the solution is monitored using a thermometer (9). The optical system consists of a light source (10) and a microscope (11). The supply of a light beam from top to bottom along the axis of the cylindrical tank and the observation along the horizontal axis allows monitoring according to the principle of ultramicroscopy. This approach allows us to record the appearance of nanosized structures at the level of $10^{-7} \mathrm{~m}$ [22]. A current is supplied from the constant voltage source $(E)$ to the electrodes, which is controlled by a voltmeter $(\mathrm{V})$ and $\mathrm{a}$ microammeter $(A)$.

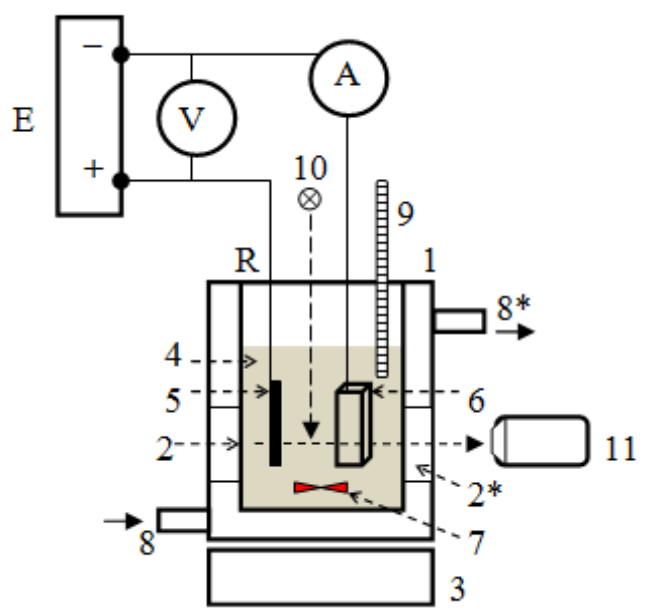

Fig. 1. Schematic diagram of the installation for electrolysis of macroions

The experiments were carried out using a carbon rod (length $40 \mathrm{~mm}, \varnothing_{5} \mathrm{~mm}$ ) and a reduction electrode - a titanium plate $(40 \times 10$ $\times 2 \mathrm{~mm}^{3}$ ) as the oxidation electrode. Since the electrolysis process is kinetic in nature, this allowed a prospecting study to choose the composition of the FB solution, temperature

and time of the experiment. Coating thickness was monitored using a SEM ZEISS (Center for Advanced Technology) instrument. 
Search studies were conducted and optimal conditions for the formation of nanocoatings with an average thickness of about $100 \mathrm{~nm}$ from a solution of chitosan (0.04\%) in $2 \%$ $\mathrm{CH}_{3} \mathrm{COOH}$ under the influence of a direct current of $2 \mathrm{~mA}$ at $50^{\circ} \mathrm{C}$ for 4 hours were determined. Under the same condition, nanocomposite nanocoatings with an average thickness of about $200 \mathrm{~nm}$ were obtained from a mixture of a solution of chitosan (0.04\%) in $2 \% \mathrm{CH}_{3} \mathrm{COOH}$ and a saturated (60\%) solution of tricalcium phosphate $\left(\mathrm{Ca}_{3}\left(\mathrm{PO}_{4}\right)_{2}\right)$ in water at a ratio of 1:1. In other conditions being equal, an increase in direct current from 2 to $8 \mathrm{~mA}$ helps to reduce the electrolysis time from 4 to 1 hour. The thickness, morphology, and composition of the coating were determined using SEM ZIESS (Center for Advanced Technology MIR) [6].

In other conditions being equal, the increase in FB from a $1 \%$ solution at $30^{\circ} \mathrm{C}$ for 1 hour. It can be seen that the surface relief of the plate is uneven and not smooth, and the roughness is in the micro-range. On the other hand, it is possible to form polymer materials without evaporating the solvent, i.e. at low electric field powers.

\section{RESULTS AND DISCUSSION}

It can be seen from Fig. 1a that there are white and gray shades between the threads of the pin that correspond to tribasic calcium phosphate and chitosan. Figure $1 \mathrm{~b}$ shows the composition of the nanocoating, which shows the reduction of chitosan and tribasic calcium phosphate macroions on the surface of a titanium implant [5]. It was revealed that a small amount of residual elements ( $\mathrm{Al}, \mathrm{Si}, \mathrm{Mg}$ ) are present in the titanium implant.

Physicochemical treatments of nanocoatings showed the stability of nanocoatings of chitosan and fibroin under the influence of weakly acidic and slightly alkaline solutions, as well as temperatures up to $150^{\circ} \mathrm{C}$.

Similar results were obtained for an aqueous solution of fibroin (0.05\%) in $50 \% \mathrm{CaCl}_{2}$. It was found that electrolysis is much more intensively realized when $4 \mathrm{~mA}$ of direct current flows through a solution of fibroin with a temperature of $50^{\circ} \mathrm{C}$ and the thickness of the nanocoating reaches $50-150 \mathrm{~nm}$ within 1 - 1.5 hours. The results of SEM analysis showed that the morphological picture of the surface of the fibroin nanocoatings is noticeably uniform in comparison with the similar picture of the surface of the chitosan nanocoatings. This, apparently, is associated with the salting out of fibroin and the formation of a salt-containing composite nanocovering [6]. Such structure formation is characteristic of electrolysis implemented according to the law of Faraday [7]. 

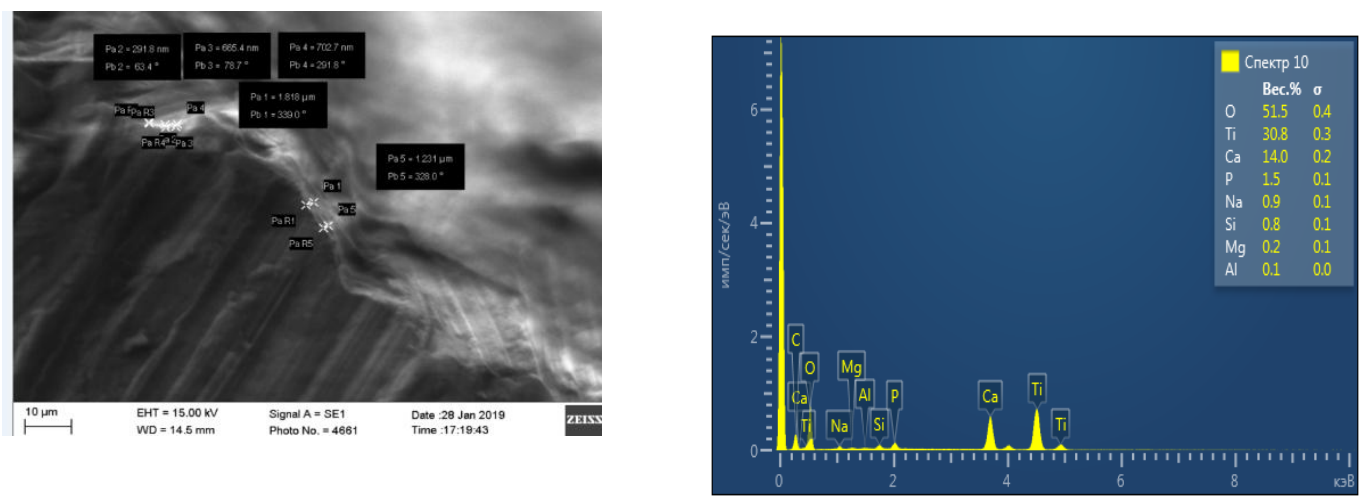

Fig.1a. SEM image of a nanocoating of chitosan and tribasic calcium phosphate on the surface of a titanium implant

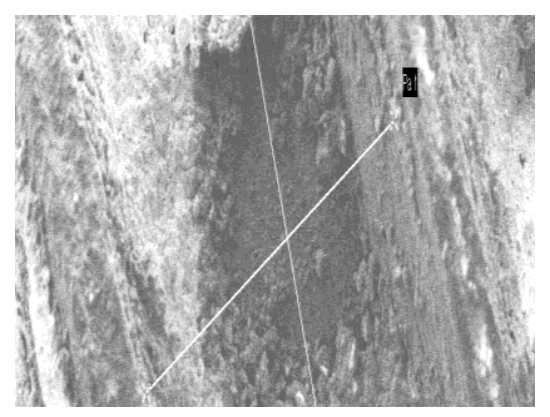

Trial electrolysis experiments showed that macroions can be effectively mixed in solutions and electrochemically reduced on the surface of various electrodes in the form of a polymer coating under the influence of direct current in the range of $1-10 \mathrm{~mA}$ and voltage of about $50 \mathrm{~V}$, i.e. with a specific electric field power of $50-500 \mathrm{~W} / \mathrm{cm}$. The formation of the coating is kinetic in nature and, depending on the time of electrolysis, it is possible to obtain a polymer coating in nanoscale thickness. Obtaining surface-active, in particular, bioactive nanocoatings based on local functionally active
Fig.1b. Spectral analysis of the composition of nanocoatings of chitosan and tribasic calcium phosphate on the surface of a pol titanium implant

ym ers on the surf ace

Fig. 2. SEM picture of FB nanocoating of tar get elec trodes, for example, on implants for dentistry and orthopedics, leads to in-depth studies both on improving the electrolysis unit and on selecting the composition of polyelectrolytes.

An urgent task is to separate large objects of sulfuric outcomes of oil and gas processing, for example, from the outcomes of the Mubarek and Kandym oil and gas processing production of ivod products. In this regard, whey is a potential source of raw materials [24]. At the same time, the creation of polymer sulfur compounds, that is, compositions with high chemical and biological activity and long-term action, is of particular interest. These types of 
compositions can be used as fungicides with an active effect against various insects, plant pests due to the biological activity of sulfur [25]. As a basis in the composition, the choice of a polymer matrix is required, which performs the function of ensuring long-term preservation of the effect of the series. This polymer is used to wash everyday life polyacrylamide (PAA) produced by JSC "Navoiazot", which is used in all types of aqueous solutions and gels (physical) in various fields. PAA gel passes into a liquid state as a result of mechanical action or dilution. This feature of the gel allows it to be mechanically processed. For example, according to the principle of two-dimensional rheology [26], by squeezing the solvent out of the gel mixture, it can be transformed from a liquid-phase composition into a solid-phase composite material. In this case, the study of their rheological properties is of practical importance. The work is devoted to the first scientific research in this area. Sulfur extracted from the waste of the Mubarek plant was selected for the study, and samples of particles ranging in size from 0.5 to $5.0 \mu \mathrm{m}$ were prepared by mechanical grinding. Polyacrylamide (PAA), obtained at JSC "Navoiazot", was dissolved in water and samples of solution and gel were prepared with a concentration of 0.1 to $10 \%$. Then, compositions of various ratios and physical conditions were prepared based on PAA and C samples (Table 1).

Table 1. Indicators of polyacryamide and sulfur compositions

\begin{tabular}{|c|c|c|}
\hline Content & Ratio, g/g/g & Physical state $\left(25^{\circ} \mathrm{C}\right)$ \\
\hline PAA: Water: $\mathrm{S}$ & $1: 100: 1$ & Medium Concentrated \\
\hline PAA: Water: $\mathrm{S}$ & $5: 100: 1$ & Visco-elastic \\
\hline PAA: Water: $\mathrm{S}$ & $10: 100: 1$ & Cel similar \\
\hline
\end{tabular}

Rheological studies of the compositions in a displacement flow were carried out in a cylinder-cylinder cell of the Reotest-2 device (Germany) [27]. Studies have also been carried out on the transformation of compositions into composites in a specially assembled 2D rheometer with a surface-to-surface cell.

The results of a rheological study performed on a Reotest-2 device are shown in Figure 2. It can be seen from the graph that with an increase in the velocity gradient, the effective viscosity decreases monotonically, and the bond curve shifts towards a larger amount of In $\eta_{\text {eff }}$, depending on the amount of polyacrylamide in the compositions. These curves can be conditionally divided into two regions: the first region is <125 s-1, in which the curves decrease in the order characteristic of a nonNewtonian fluid, and the viscosity in the second plow is> $125 \mathrm{~s}^{-1}$. It is almost constant, which is typical for a Newtonian fluid. 
This type of graph is associated with the conformational change in PAA molecules in shear flow, in which sulfur particles mainly perform a thickening function. When the shear flow was stopped, all three compositions went into a gel state. In such gel structures, sulfur particles are involved in the formation of bonds and knots.

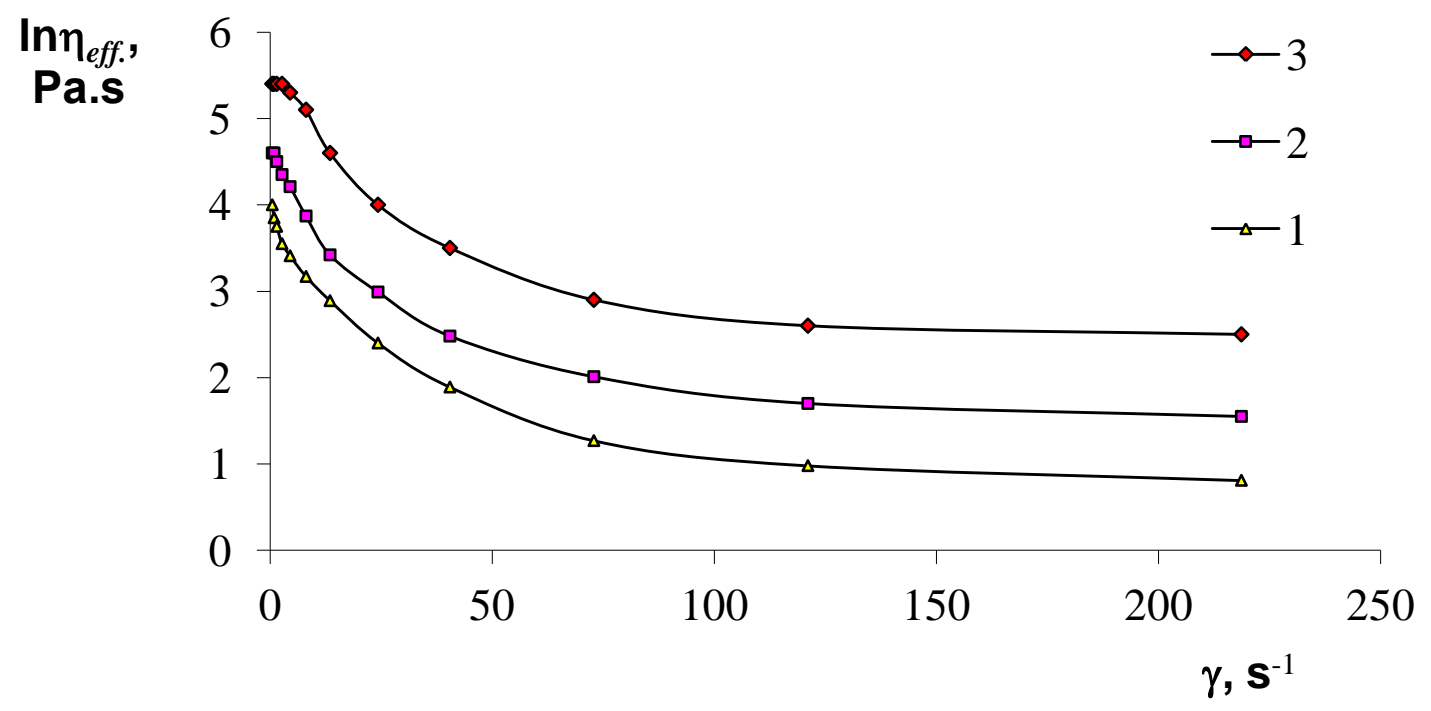

Fig 3. Dependence of effective viscosity (In

1 - PAA: water: S (1: 100:1); 2 - PAK: water: S (5: 100:1); 3 - PAA: water: S (10: 100: 1)

The process that occurs in the surface-tosurface cell according to the principle of twodimensional rheology is schematically illustrated in Figure 3. In this case, the rotor surface (a) rotates at a given speed, compressing the composition (b) to a fixed surface (c). The fixed surface has a mesh structure (hole size $50 \mu \mathrm{m}$ ), from the holes of which the solvent (g), that is, water, is squeezed out. The rotor speed decreases from 10 to $0.1 \mathrm{rpm}$, and the gel-like liquidphase composition (b) turns into a solid-phase composite state. The volume of the gel phase is reduced from 2 to 5 times.

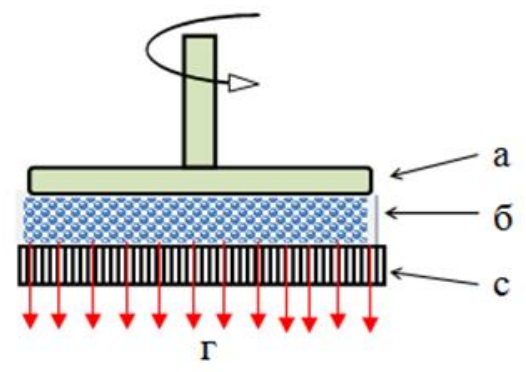

Fig 4. Schematic representation of a surface-to-surface cell of a 2D rheological device. 
In the composite obtained by this method, it was found that the sulfur particles were uniformly distributed throughout the volume of the polyacrylamide matrix. Thus, twodimensional rheological studies have shown the possibility of obtaining thin-layer composites based on PAA: $\mathrm{S}$.

\section{CONCLUSION}

Thus, the possibility of forming a nanocoating of biocompatible fibroin during electrolysis, i.e. by restoring the ionic groups of this protein on the surface of a titanium plate. Despite the fact that the surface roughness of the plate is in the micro-range, it significantly affects the formation of the FB coating with different thicknesses in the nanoscale range. Thus, as a result of rheological studies, the possibility of the transition of polyacrylamide and sulfur-containing compositions from the state of solution to the gel state in a cell of the "cylinder-cylinder" type and the transition of the gel composition to the solid-phase composite state was established. in a cell of the "surface-cell" type.

\section{REFERENCES}

1. Podvigalkin Ya., Muzalev., PA, Ushakov NM, Kosobudskiy ID. Nanomaterials and nanotechnology. Electronic engineering materials. 2012. p. 2. P.51.

2. Nalwa H.S. Nanostructured Materials and Nanotechnology. Ed.. Academ. Press: San Diego. CA. 2002. P. 428.

3. Pomogailo AD, Rosenberg AS, Uflyand IE .. Nanoparticles of metals in polymers. M.: Nauka, 2006.350 p.

4. Torsuev D.M., Konopleva A.A., Barabanov V.P., Vyaseleva G.Ya. // Bulletin of Kazan
Technological University, 2014, Vol. 1, p. 144-147.

5. Zenghua Geng, Xia Wang, Xuecheng Guo et all // Journal of Materials Chemistry. B. 2016. V.4. P. 3331.

6. Patake1 V.D., Ghogare1 T.T., Gulbake1 A.D., Lokhande1 C.D.//SN Applied Sciences. 2019. V.1. P.1063.

7. Marguerite Rinaudo //Progress in Polymer Science. 2006. V.31. №7. P. 603.

8. Skryabin K.G., Vikhoreva G.A., Varlamov V.P. Chitin and chitosan: Preparation, properties and application // Moscow, Nauka. 2002.360 p.

9. Tenchurin T.Kh., Sharikov R.V., Chvalun S.N. // Russian nanotechnology. 2019. Volume 14, No. 7-8. P. 3.

10. Ya Yang, Hui Wang, Jia-Chen Zhu et al. // ACS Biomaterials Science \& Engineering. 2019. V.5. № 9. P. 4302.

11. Thamm C., Scheibel T. // Biomacromolecules. 2017. V. 18. № 4. P. 1365.

12. Safonova L.A., Bobrova M.M., Agapova O.I. et al. // Bulletin of transplantology and artificial organs. 2016.T.18. No. 3. P 73.

13. Nan Chen, Do Han Kim, Peter Kovacik et al. // Annu. Rev. Chem. Biomol. Eng. 2016. №7. P. 373.

14. Pavlenko A.V., Tokarskiy V.F., Prots G.B. et al. // Modern dentistry. 2013. No. 1. P. 89.

15. Isakova D. et al. // Universum: Chemistry and biology: electron. scientific. zhurn. 2019. P (62).

16. Luis F. Arenas, Carlos Ponce de Leon, Richard P. Boardman et al //Journal of The Electrochemical Society. 2017. V.1 64. №2. P. 57.

17. Ramachandra Rao $\mathrm{R}$ et al //Int. J. ChemTech Res. 2014. V.7. № 5. P. 2117. 
18. Zhang Y.Q. // Biotechnol Adv. 2002. V.20. № 2. P.:91

19. Mohsan Akhter, Ghulam Habib, Sana Ullah Qamar// J Membr Sci Technol. 2018. V.8. №2. P.2.

20. Kholmuminov A.A. Dis. "Orientational structure formation of silk fibroin with anisotropic properties in solutions" Dr. fiz.-mat. sciences. Tashkent, AN RUz ICFP. 2008.

21. Matveenko V.N., Kirsanov E.A. // News. Moscow University. Ser. 2. Chemistry. 2011.752. No. 4. P. 243.

22. Hans-Ulrich Dodt1, Ulrich Leischner, Anja Schierloh et al. //Nature methods / 2007. V.4. No. 4. p. 331.

23. Ivanov V.E., Chernikov A.V., Gudkov S.V. //Biophysics. 2015.V.63. no. 5, p. 873.

24. Massalimov I.A., Udovenko I.F., Kireeva M.S., Vixareva I.N. Primenenie vodnyx serosoderjashix kompozitsiy $v$ kachestve sredstv zashity rasteniy //Bashkirskiy ximicheskiy jurnal. 2006. T 13. №4. S. 97100.

25. Patel P, Tyagi S, Patel CJ, Patel J. Recent advances in novel semisolid dosage forms: An overview // Journal of biomedical and pharmaceutical research. 2013. № 2 (1). P. 9-14.

26. Derkach S.R., Kragel J., Miller R. Metody izmereniya reologicheskix svoystv mejfaznyx sloev. Obzor (Eksperimentalnye metody $2 \mathrm{D}$ reologii) //Kolloidnyy jurnal, 2009. Tom 71, №1, s. 552.

27. Malkin A. YA. Reologiya: konsepsii, metody, prilojeniya // avtoriz. per. s angl. Malkin A. YA., Isaev A. I.- SPb.:Professiya. 2007. $210 \mathrm{~s}$. 